\title{
Densification Behavior and Microstructure Evolution of Mo Manocrystals by Microwave Sintering
}

\author{
Ruihu Wang, ${ }^{1,2}$ Shilei Li, ${ }^{1}$ Peng Hu, ${ }^{1, *}$ Shuqun Chen ${ }^{1}$ and Jinshu Wang ${ }^{1, *}$
}

\begin{abstract}
Fabrication of full-densified Mo metal with fine grain size and uniform microstructure is highly desired to improve its mechanical property. In this work, microwave-field-assisted thermal sintering was utilized to promote the fast densification of Mo nanocrystals, and the compact with high relative density of $99.8 \%$ and fine grain size of $2.09 \mu \mathrm{m}$ was obtained at $1450{ }^{\circ} \mathrm{C}$ for $0.5 \mathrm{~h}$ with heating rate of $20^{\circ} \mathrm{C} / \mathrm{min}$, which is much superior to the compact with density of $99.13 \%$ and grain size of $7 \mu \mathrm{m}$ fabricated by traditional thermal sintering at $1500^{\circ} \mathrm{C}$ for $1 \mathrm{~h}$. Further theoretical and experimental investigation reveals that effective volume heating transfer with low activation energy provides strong driven-force for densification of nanosized Mo powder at low temperature.
\end{abstract}

Keywords: Nanocrystalline molybdenum; Microwave sintering; Densification; Kinetics; Multiphysics simulation. Received date: 1 February 2021; Accepted date: 11 March 2021.

Article type: Research article.

\section{Introduction}

As a typical refractory metal, molybdenum has been widely applied in metallurgy, chemical engineering and aerospace fields owing to its excellent properties such as high strength, superior electrical and thermal conductivity and superior corrosion resistance ${ }^{[1-3]}$ Due to its high melting point of 2893 $\mathrm{K}$, Mo components are usually fabricated by powder metallurgy process at rather high sintering temperatures, which usually results in the over-coarsened grains with negative effect on mechanical properties.${ }^{[4]}$ In order to improve the sintering activity of molybdenum, refining the particle size has been recognized as a feasible strategy. It has been widely illustrated that fine nanopowders can effectively enhance their sintering activity due to its high specific surface areas ${ }^{[5]}$ In our previous work, quasi-spherical Mo nanopowders with average size of $30 \mathrm{~nm}$ was synthesized by thermal plasma synthesis route, and the sintering results illustrate that Mo compact with a relative density of $99.13 \%$ and grain size of $7 \mu \mathrm{m}$ is achieved at the low temperature of $1500{ }^{\circ} \mathrm{C} .{ }^{[6]}$ Although nanocrystal sintering could effectively promote the densification and suppress grain coarsening, as-fabricated compact still

\footnotetext{
${ }^{1}$ Key Laboratory of Advanced Functional Materials, Education

Ministry of China, Faculty of Materials and Manufacture, Beijing

University of Technology, Beijing, 100124, China.

2 School of Metallurgical Engineering, Xi'an University of

Architecture and Technology, Shaanxi, 710043, China.

*Email: pengh@bjut.edu.cn (P. Hu); wangjsh@bjut.edu.cn (J. Wang)
}

possesses over-large grain size which needs to be further solved.

As the critical process of the powder metallurgy technology, heating way plays a decisive role in the microstructure of the final product. Different from the heating mechanism of radiation and conduction in the conventional sintering process, microwave sintering can directly transfer heat to the materials through the coupling of electromagnetic waves, which leads to volumetric heating in the microwave field with enhanced heating efficiency, ${ }^{[7-9]}$ and also possesses the feasibility for bulk component fabrication compared to spark plasma sintering. Recent work found that microwave sintering could achieve alloys with carefully designed microstructure and result in improved mechanical properties. ${ }^{[10-13]}$ Chhillar et al. studied the microwave sintering process of micro sized molybdenum powder, and illustrated that increased density and decreased grain size could be obtained at a lower sintering temperature compared with the conventional sintering. ${ }^{[14]}$ Duan et al. further investigated the kinetics mechanism of molybdenum powder during microwave sintering process, and concluded that microwave is beneficial to enhance the atomic diffusion and thus promote the densification process. ${ }^{[15]}$ Although fine grain size of $3.6 \mu \mathrm{m}$ was achieved in their work, $98.03 \%$ relative density suggests the non-fully completed densification process. Up to now, the reports on microwave sintering of metal materials are still far less than traditional thermal sintering and spark plasma sintering. In addition, the theoretical investigation of the 

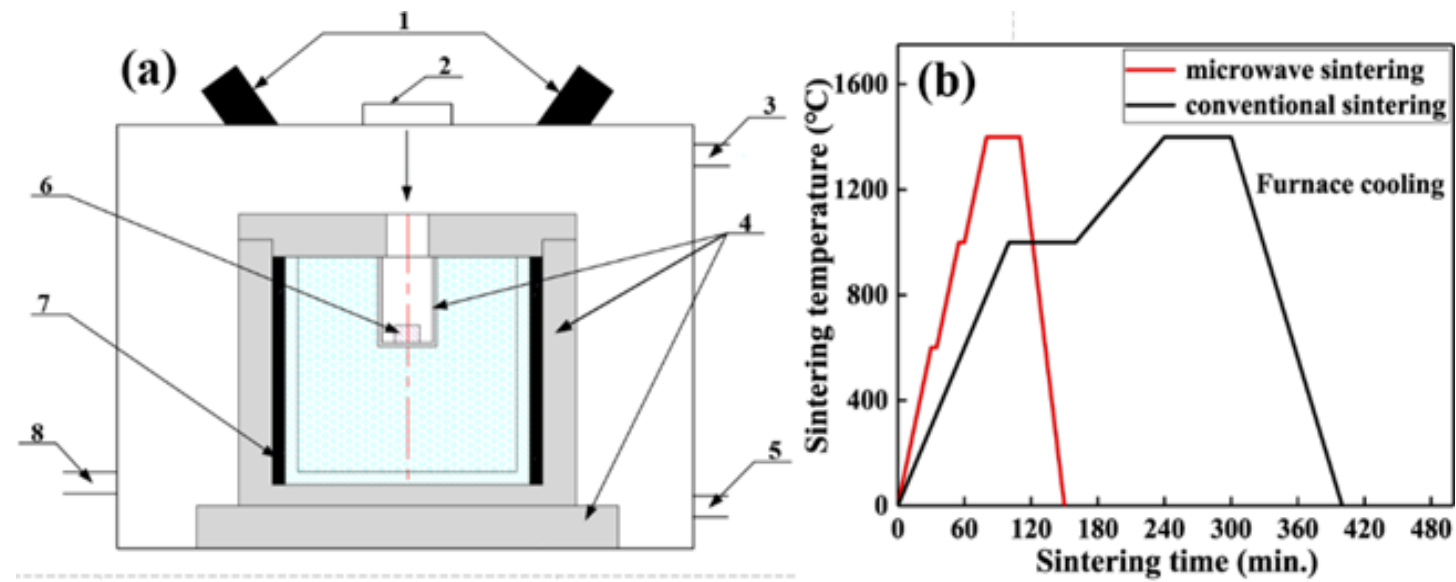

Fig. 1 (a) Schematic diagram of insulation barrel structure: 1. Microwave source 2. Infrared thermometer 3. Gas inlet 4. Alumina fiber 5. Vacuum pump inlet 6. Sample 7. Silicon carbide 8. Gas outlet, (b) Heating curve of microwave sintering and conventional sintering.

heating mechanism of microwave sintering is also seldom be reported, and understanding the fast heating process is beneficial to further promote the densification of metal compact, and also significant to fabricate other refractory metal based compacts with high density.

In this work, the densification behavior and microstructure evolution of quasi-spherical molybdenum nanopowder during microwave sintering process was investigated, and its densification kinetics and multi-physics simulation were also conducted to understand the intrinsic sintering mechanism. The results show that enhanced heating efficiency in the microwave field greatly decreases the sintering activation energy with enhanced densification degree, and results in the formation of full-densified Mo metal with fine grain size. Accordingly, molybdenum compact with a relative density of $99.8 \%$ and grain size of $2.09 \mu \mathrm{m}$ was rapidly fabricated at rather low temperature of $1450{ }^{\circ} \mathrm{C}$ for $30 \mathrm{~min}$, which is significantly superior to the compact obtained by traditional sintering process.

\section{Experimental}

\subsection{Fabrication of Mo compacts}

Nanocrystalline molybdenum powder was synthesized by thermal plasma synthesis route as illustrated in our previous work, ${ }^{[6]}$ and as obtained powder was then pressed at $400 \mathrm{MPa}$ for $5 \mathrm{~min}$ to form the green compact with diameter and thickness of $10 \mathrm{~mm}$ and $1 \mathrm{~mm}$, respectively. The relative density was determined to be about $47.6 \%$ of theoretical density.

Microwave sintering was performed on a $4.5 \mathrm{KW}, 2.45$ $\mathrm{GHz}$ microwave furnace (HAMiLab-VS4500, Changsha syno-therm Co., China), and a schematic illustration of the microwave reactor is shown in Fig. 1a. In a typical experiment, the mixed gas including $8 \% \mathrm{H} 2$ and $92 \% \mathrm{Ar}$ in volume ratio was firstly introduced into reactor and then bled by extracting pump. This process was repeated three times to remove residual air. After that, the sintering was conducted and the heating curve is shown in Fig. 1b. As indicated, the samples were firstly kept at $600{ }^{\circ} \mathrm{C}$ and $1000^{\circ} \mathrm{C}$ for 5 min to effectively release internal residual stress, and then heated to different temperature with set heating rate and holding time. The sintering temperature was measured in real time by an Infrared thermometer located on the top of the furnace. During the whole process, the mixed gas was continually injected to keep the reducing atmosphere. As a reference, the green compacts were also sintered in tubular furnace under the same atmosphere without microwave field.

\subsection{Characterization}

The phase of molybdenum powder and sintered samples were analyzed by X-ray diffractometer (SHIMADZU XRD-7000). The microstructure and morphology of molybdenum nanopowder and sintered compacts were characterized by scanning electron microscope (FE-SEM, Hitachi SU8020). The fine structure of nano-molybdenum powder was investigated by transmission electron microscope (TEM, TALOS JEM-2010). The density of the sintered sample was measured with a density tester (ETNALN, ET-320M) by the Archimedes principle. The linear shrinkage of the sintered sample was characterized by calculating the changes in radial length. The grain size was measured by Nano Measurer software with calculating 100 grains. The Vickers hardness of the sintered samples was conducted on a Microhardness Tester (HXP-2000TM) with a load of $200 \mathrm{gf}$ for $15 \mathrm{~s}$, and the average hardness was obtained by testing 10 times for each sample.

\subsection{Multiphysics simulation}

The electromagnetic field distribution during microwave sintering was simulated by finite element simulation using COMSOL Multiphysics software. By solving Maxwell's equations, ${ }^{[16-18]}$ the electromagnetic field distribution intensity in the microwave field cavity can be obtained. The frequency value of the magnetron is set to $2.45 \mathrm{GHz}$, and the cavity was energized by microwave propagating through three standard Magnetrons in the $\mathrm{TE}_{10}$ mode at $800 \mathrm{~W}$. 

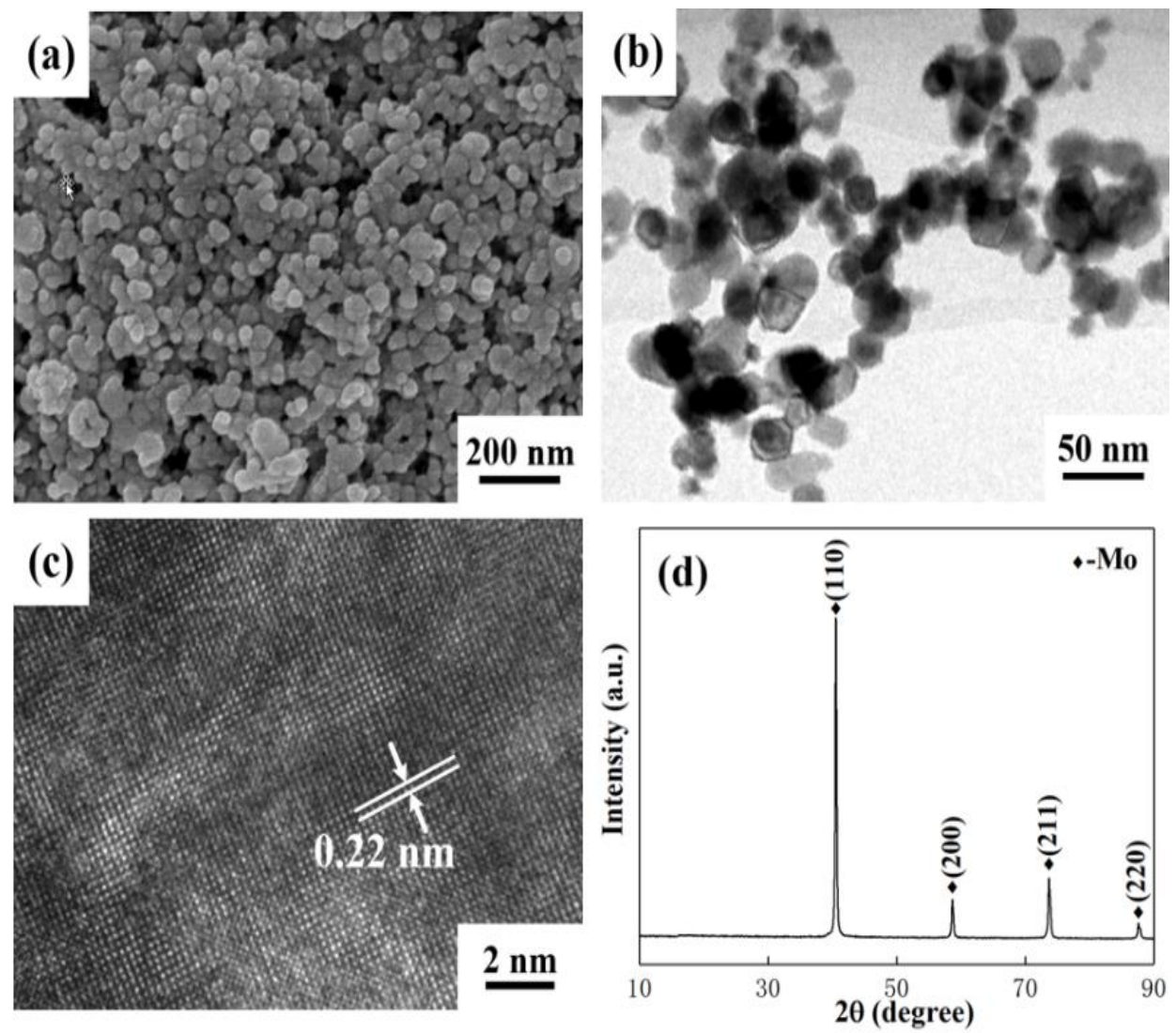

Fig. 2 (a) SEM, (b) TEM, (c) HRTEM and (d) XRD images of molybdenum nanopowders synthesized by thermal plasma.

\section{Results and discussion}

\subsection{Microstructure of molybdenum nanoparticles}

The typical morphology and microstructure of molybdenum nanopowders synthesized by thermal plasma are shown in Fig. 2. SEM image illustrates the quasi-spherical shape and well dispersion of obtained nanoparticles as shown in Fig. 2a. TEM image in Fig. $2 b$ further indicates that the average size of the prepared molybdenum nanopowder was about $30 \mathrm{~nm}$. Fig. $2 \mathrm{c}$ presents the HRTEM image of obtained nanopowder, and the clear lattice fringe image illustrates its high crystallinity. The lattice distance of about $0.22 \mathrm{~nm}$ was determined by measuring the adjacent lattice spacing, which is well
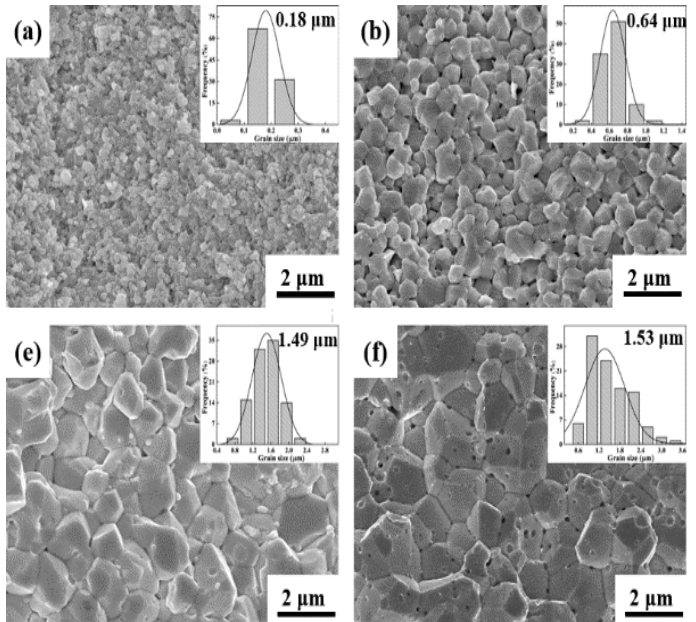

corresponding to the (110) plane of the molybdenum crystal. XRD pattern of the molybdenum powder is shown in Fig. 2d, and all the diffraction peaks are well assigned to the bodycentered cubic structure of molybdenum (JCPDS 42-1120) without oxides or other compounds detected.

\subsection{Microstructure evolution of Mo compacts sintered at different temperatures}

Microstructural evolution during sintering process was investigated by analyzing the fracture surface of compacts obtained at different temperature as shown in Fig. 3. It can be clearly seen that the intergranular brittle fracture is the
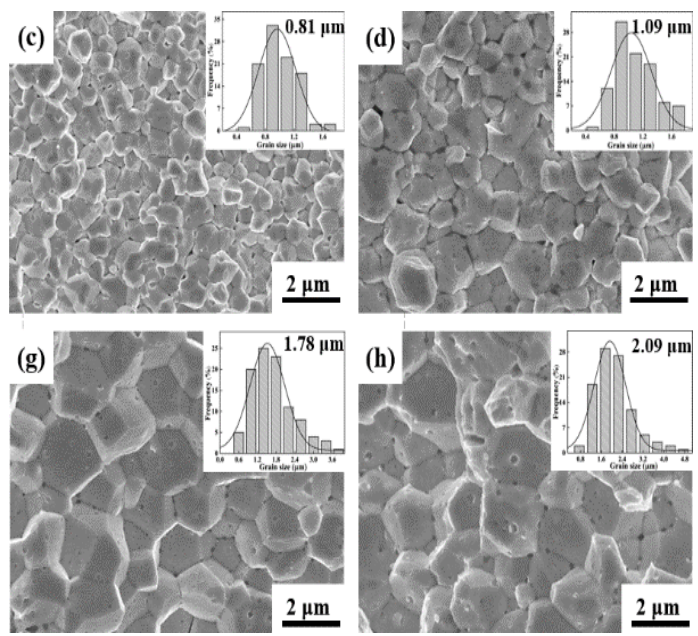

Fig. 3 SEM fracture images and grain distribution histogram of samples produced by microwave sintering for $0.5 \mathrm{~h}$ at different temperatures: (a) $1100{ }^{\circ} \mathrm{C}$, (b) $1150{ }^{\circ} \mathrm{C}$, (c) $1200{ }^{\circ} \mathrm{C}$, (d) $1250^{\circ} \mathrm{C}$, (e) $1300{ }^{\circ} \mathrm{C}$, (f) $1350{ }^{\circ} \mathrm{C}$, (g) $1400{ }^{\circ} \mathrm{C}$ and (h) $1450{ }^{\circ} \mathrm{C}$. 
dominant fracture mode for Mo. When the sintering temperature increased from $1100^{\circ} \mathrm{C}$ to $1150{ }^{\circ} \mathrm{C}$ (as shown in Fig. $3 \mathrm{a}$ and $\mathrm{b}$ ), obvious aggregation of particles with the generation of sintered neck (as inset shown in Fig. 3b) could be clearly observed, and resulted in the formation of nondense compacts. When the temperature further increased from $1200{ }^{\circ} \mathrm{C}$ to $1250^{\circ} \mathrm{C}$ (Fig. 3c and d), continuous grain growth proceeded and led to the sharp decrease of pore numbers among the grains. During this stage, the shape of grains was also changed to multi-faceted to obtain lower grain-boundary energy. It should be noted that the grain size started to beyond micrometer at the temperature of $1250{ }^{\circ} \mathrm{C}(1.09 \mu \mathrm{m})$. With the holding temperature elevating from $1300{ }^{\circ} \mathrm{C}$ to $1350{ }^{\circ} \mathrm{C}$, the size of the grains increased from 1.49 to $1.53 \mu \mathrm{m}$, and the pores in grains continuously shrunk and then migrated to grain boundaries through mass transport, indicating the almost completed densification process. As the sintering temperature further increased from $1400{ }^{\circ} \mathrm{C}$ to $1450{ }^{\circ} \mathrm{C}$ as shown in Fig. $3 \mathrm{~g}-\mathrm{h}$, the pores located at the grain boundary gradually disappeared and the full-densified compact with grain size of $2.09 \mu \mathrm{m}$ was obtained at $1450{ }^{\circ} \mathrm{C}$ with almost completely disappeared pores.

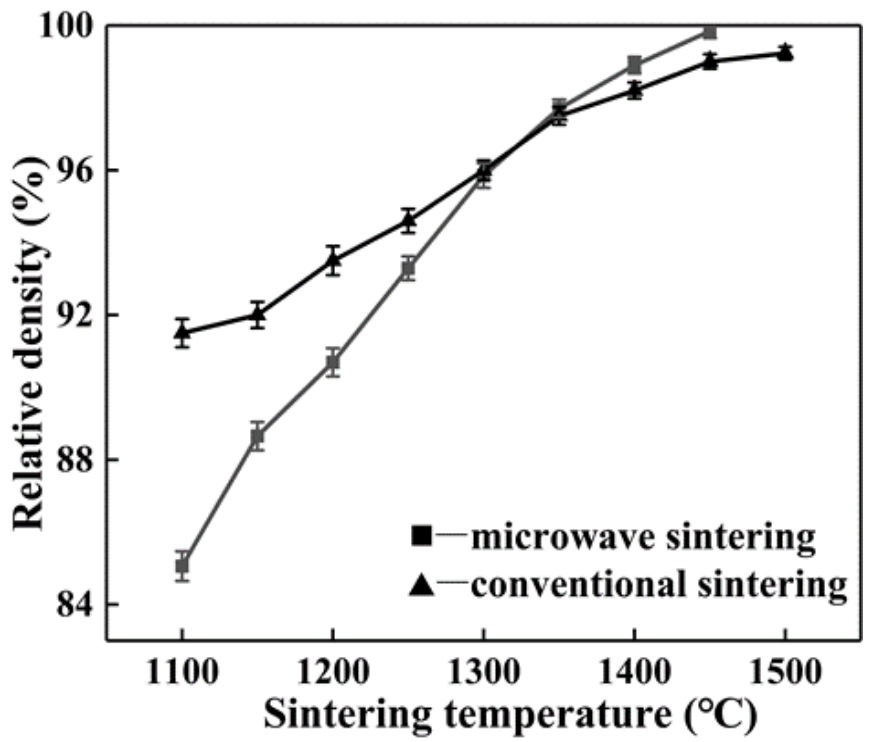

Fig. 4 Effect of sintering temperature on the relative density of the Mo samples obtained by microwave sintering and conventional sintering.

Fig. 4 shows the comparison of relative density of molybdenum samples obtained by microwave sintering and thermal sintering in tubular furnace without microwave field at different sintering temperatures. With the increase of sintering temperature, the density of two samples continuously increased, but the increase rates could be clearly divided into two regions around $1300{ }^{\circ} \mathrm{C}$. At the temperature below $1300{ }^{\circ} \mathrm{C}$, the densification rates of the conventionally sintered samples increased faster than that of sample produced by microwave sintering, resulting in higher density. However, a reversed tendency was observed when the temperature was higher than $1300{ }^{\circ} \mathrm{C}$. Fast densification rates of microwave sintering were observed and led to the higher relative density than the thermal sintered samples without microwave field. The results indicate that microwave field is more efficient to improve the densification at high temperature. Impressively, the compact with a grain size of $2.09 \mu \mathrm{m}$ and relative density of $99.8 \%$ was obtained by microwave sintering at $1450{ }^{\circ} \mathrm{C}$, which is even superior to the sample obtained by thermal sintering at $1500{ }^{\circ} \mathrm{C}$ for $1 \mathrm{~h}$ (density of $99.13 \%$ and grain size of $7 \mu \mathrm{m}$ ), illustrating the advantage of microwave field on promoting the sintering densification with well suppressed grain growth.

In microwave sintering, there are two heating matters that drive the densification of powders. One is the volume heating originated from arc discharge and magnetic loss mechanisms of metal in microwave field, and the other is the supplementary heating by microwave absorbed silicon carbide At the low temperature, the porous structure of compact limited the volume heating efficiency, ${ }^{[19]}$ and the densification was mainly promoted by the heated silicon carbide through heat radiation and conduction. Because of the fast heating rate, the sintering time was much shorter than conventional thermal sintering, thus led to the formation of porous compact with low density. When the temperature increased, the arc discharge and magnetic loss in metal were dominant due to the decreased porosity, ${ }^{[20]}$ and the various thermal and non-thermal effects induced by microwave field were also enhanced, ${ }^{[21]}$ which all greatly improved the volume heating efficiency with sharply enhanced densification rates, and resulted in the highly densified compact with much fine grain size than conventional thermal sintering.
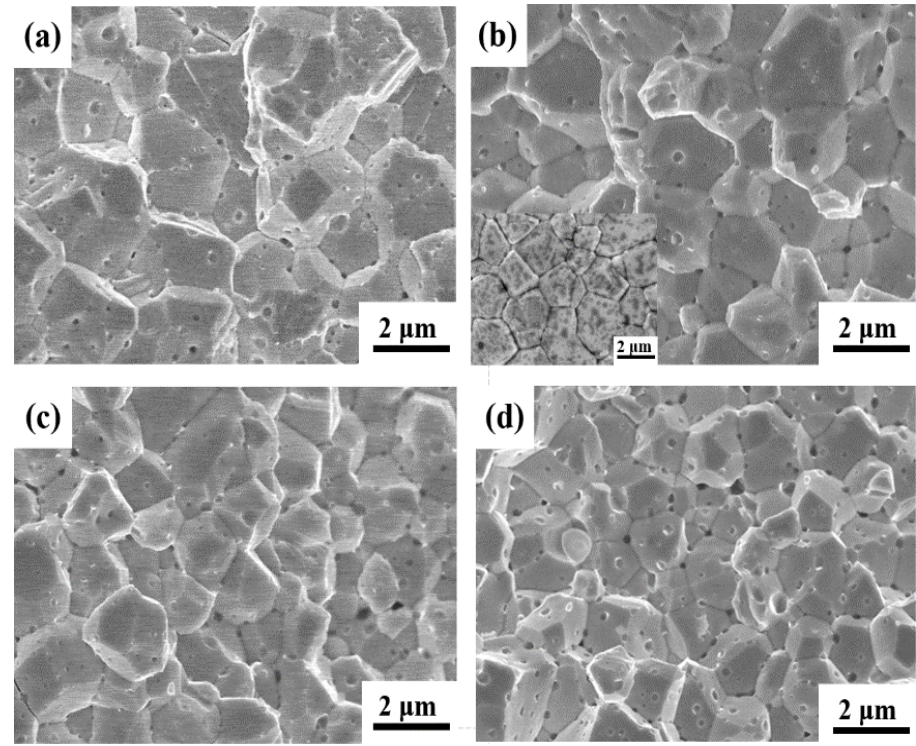

Fig. 5 SEM fracture images of samples microwave sintered at $1450{ }^{\circ} \mathrm{C}$ for $0.5 \mathrm{~h}$ at different heating rates: (a) $10{ }^{\circ} \mathrm{C} / \mathrm{min}$, (b) $20{ }^{\circ} \mathrm{C} / \mathrm{min}$, (c) $30{ }^{\circ} \mathrm{C} / \mathrm{min}$ and (d) $40{ }^{\circ} \mathrm{C} / \mathrm{min}$.

\subsection{Microstructure evolution of Mo compacts sintered at different heating rates}

Fig. 5 shows the fracture surface of the samples sintered at $1450{ }^{\circ} \mathrm{C}$ for $0.5 \mathrm{~h}$ with different heating rates. With the heating 
rate increased from $10{ }^{\circ} \mathrm{C} / \mathrm{min}$ to $40{ }^{\circ} \mathrm{C} / \mathrm{min}$, the average grain size of the sintered samples was quickly reduced from $2.4 \mu \mathrm{m}$ to $1.4 \mu \mathrm{m}$, but the size distribution became non-uniform at high heating rate of $40{ }^{\circ} \mathrm{C} / \mathrm{min}$. In microwave sintering process, the heating rate was mainly controlled by input power, and high input power tended to cause the locally over-heated sites with non-uniform thermal effect, ${ }^{[22-23]}$ and over-grown grain at these sites resulted in the large difference in gain size. In addition, the phenomenon even led to deformation and cracking in the sintered product. ${ }^{[24]}$

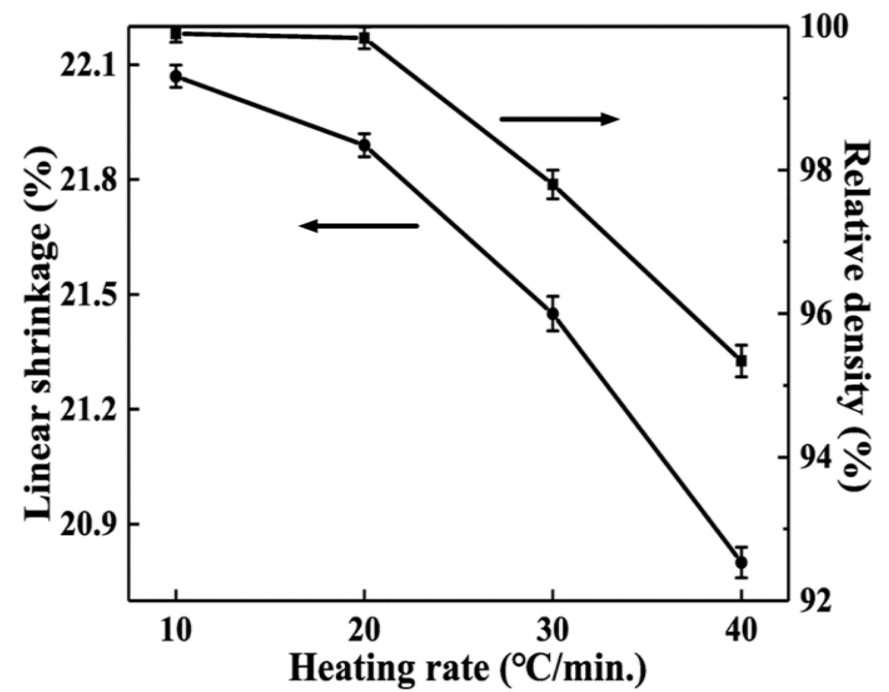

Fig. 6 Effect of different heating rate on relative density and linear shrinkage of microwave sintered samples at $1450{ }^{\circ} \mathrm{C}$ for $0.5 \mathrm{~h}$.
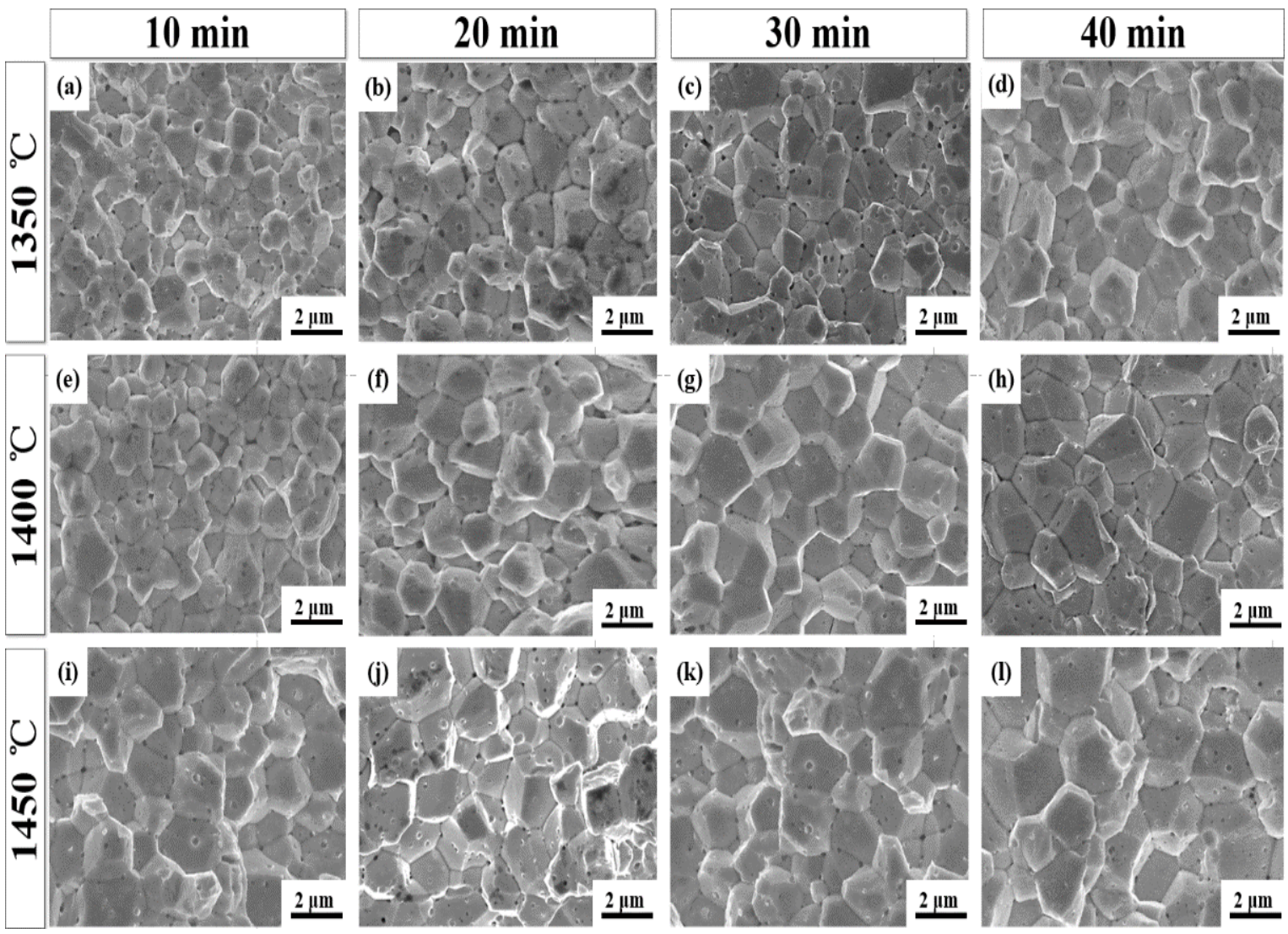

Fig. 7 SEM fracture images of samples microwave sintered at $1350{ }^{\circ} \mathrm{C}, 1400{ }^{\circ} \mathrm{C}$ and $1450{ }^{\circ} \mathrm{C}$ with different holding time.
In addition, the heating rates also have great influence on the relative density and linear shrinkage of obtained compact. As shown in Fig. 6, both of the relative density and linear hrinkage were decreased with the increased heating rate, and $.56 \%$ and $1.26 \%$ decrease in relative density and linear shrinkage could be observed for the sample obtained at heating te of $40{ }^{\circ} \mathrm{C} / \mathrm{min}$ compared to that obtained at $10{ }^{\circ} \mathrm{C} / \mathrm{min}$. herefore, reasonable control of the heating rate of the intering process is necessary to adjust the density and grain size of compact with uniform microstructure by microwave

\subsection{Microstructure evolution of Mo compacts sintered with} different holding time

The fracture surface of the samples sintered at 1350,1400, and $1450{ }^{\circ} \mathrm{C}$ with different holding times are shown in Fig. 7, and it is clear that the holding time had little effect on the grain size of the microwave sintered compacts compared with sintering temperature. At the temperature of $1350{ }^{\circ} \mathrm{C}$, the average grain size increased from $1.23 \mu \mathrm{m}$ to $1.58 \mu \mathrm{m}$ with the holding time increasing from $10 \mathrm{~min}$ to $40 \mathrm{~min}$, while the increase from $1.66 \mu \mathrm{m}$ to $1.95 \mu \mathrm{m}$ and $1.97 \mu \mathrm{m}$ to $2.29 \mu \mathrm{m}$ were observed at $1400{ }^{\circ} \mathrm{C}$ and $1450{ }^{\circ} \mathrm{C}$, respectively. In addition, the relative densities were also continuously increased due to the proceeded densification process from 10 min to $40 \mathrm{~min}$, and the increase from $94.7 \%$ to $97.6 \%$ at $1350{ }^{\circ} \mathrm{C}, 95.9 \%$ to $98.5 \%$ at $1400{ }^{\circ} \mathrm{C}$ and $96.8 \%$ to $99.8 \%$ at $1450{ }^{\circ} \mathrm{C}$ were observed, respectively. 

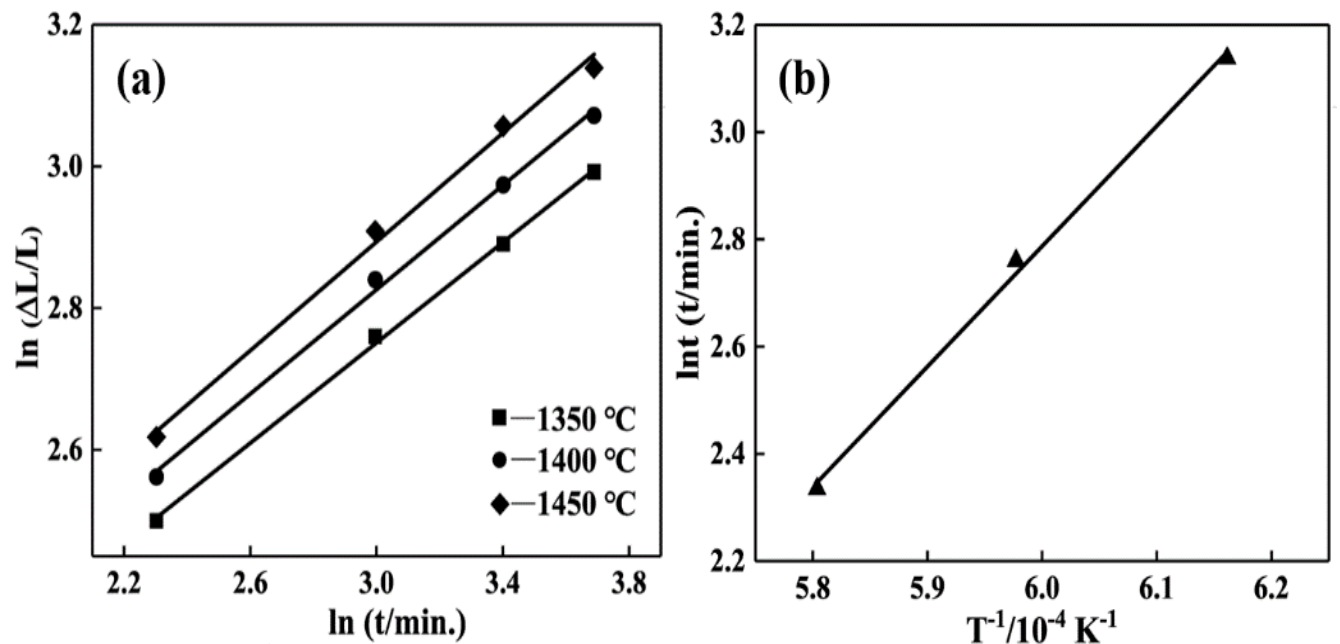

Fig. 8 (a) Sintering kinetic curves of compacts microwave sintered at different temperature, (b) relationship curve between ln $t$ and $1 / \mathrm{T}$.

3.5 Densification kinetics of Mo during microwave sintering process

According to the empirical sintering law, the rate equation of the sintering process can be expressed as follows: ${ }^{[25]}$

$$
\begin{aligned}
\frac{\Delta L}{L} & =A(T) \cdot t^{\frac{1}{n}} \\
\ln \frac{\Delta L}{L} & =\frac{1}{n} \ln t+\ln A(T)
\end{aligned}
$$

where $\frac{\Delta L}{L}$ is the linear shrinkage of the sample; $A(T)$ is a constant related to the sintering temperature; $t$ is the sintering time ( $\min$ ), and $n$ is the sintering characteristic index which can be used to determine the mass migration mechanism during the sintering process.

According to Eq. (2), it can be clearly seen that $\ln \frac{\Delta L}{L}$ has a linear relationship with $\ln t$ and the slope of line is $1 / n$. Therefore, the characteristic index $n$ of the sintering kinetic equation can be determined by calculating the slope of the line. Using the relative shrinkage values of the samples sintered at 1350, 1400 and $1450{ }^{\circ} \mathrm{C}$ with different sintering time, the linear relationship between $\ln \frac{\Delta L}{L}$ and $\ln t$ can be obtained as shown in Fig. 8a. Through linear regression processing, sintering kinetic equations at different temperatures can be obtained as shown below:

$$
\begin{aligned}
1350^{\circ} \mathrm{C}: \ln \frac{\Delta L}{L} & =0.3539 \ln t+1.6893 \\
& =\frac{1}{2.8257} \ln t+1.6893 \\
1400{ }^{\circ} \mathrm{C}: \ln \frac{\Delta L}{L} & =0.3674 \ln t+1.7243 \\
& =\frac{1}{2.7218} \ln t+1.7243 \\
1450{ }^{\circ} \mathrm{C}: \ln \frac{\Delta L}{L} & =0.3836 \ln t+1.7429 \\
& =\frac{1}{2.6069} \ln t+1.7429
\end{aligned}
$$

The volumetric diffusion is the main migration mechanism at $n=2.5$, while the grain boundary diffusion is the main migration mechanism at $n=3$. According to the results of Eqs. (3), (4) and (5), $n$ at the three temperatures were determined as $2.8257,2.7218$ and 2.6069 , respectively. Therefore, the densification of the molybdenum nanopowder during the microwave sintering could be ascribed to the combination of the grain boundary diffusion and volumetric diffusion. Furthermore, the values of $\mathrm{n}$ are decreased with the increase in the sintering temperature, indicating that the volumetric diffusion gradually becomes the dominant migration way.

According to the Arrhenius formula, the relationship between the sintering rate $\mathrm{K}$ and the temperature $T$ can be expressed as:

$$
\begin{aligned}
& \mathrm{K}=\frac{1}{t}=B e^{-\frac{Q}{R T}} \\
& \ln t=\ln B+\frac{Q}{R T}
\end{aligned}
$$

where $Q$ is the sintering activation energy, $\mathrm{kJ} / \mathrm{mol} ; B$ is the experiment constant; $R$ is the molar gas constant, 8.314 $\mathrm{J} / \mathrm{mol} \cdot \mathrm{K}, T$ is the thermodynamic temperature $(\mathrm{K})$. It can be seen from Eq. (7) that $\ln t$ has a linear relationship with $\frac{1}{T}$, and $\frac{Q}{R}$ presents the slope of the line. Thus the activation energy of microwave sintering can be obtained by calculating the slope of the line shown in Fig. 8a. Taking $\ln \frac{\Delta L}{L}=2.8$, we can get three sets of lnt values corresponding to different temperatures, and the obtained thermodynamic curve is presented in Fig. 8b. Through the linear regression processing, the thermodynamic equation can be obtained as follows

$$
\text { lnt }=2.2436 \times 10^{4} \cdot \frac{1}{T}-10.6741
$$

By calculating the slope of the line, the sintering activation energy under the microwave field is calculated to be 186.53 $\mathrm{kJ} / \mathrm{mol}$. Compared with the traditional sintering of pure molybdenum microsized powders ( $Q$ is about $254 \mathrm{~kJ} / \mathrm{mol}$ ), the activation energy of nanosized molybdenum powder is effectively decreased during the microwave sintering process, which is responsible for the formation of fine-grained and fully densified compact at rather low temperature of $1450{ }^{\circ} \mathrm{C}$.

\subsection{Microhardness evolution of obtained compacts}

Fig. 9 gives the microhardness evolution of compacts obtained at different sintering parameters. As shown in Fig. 9a, the 

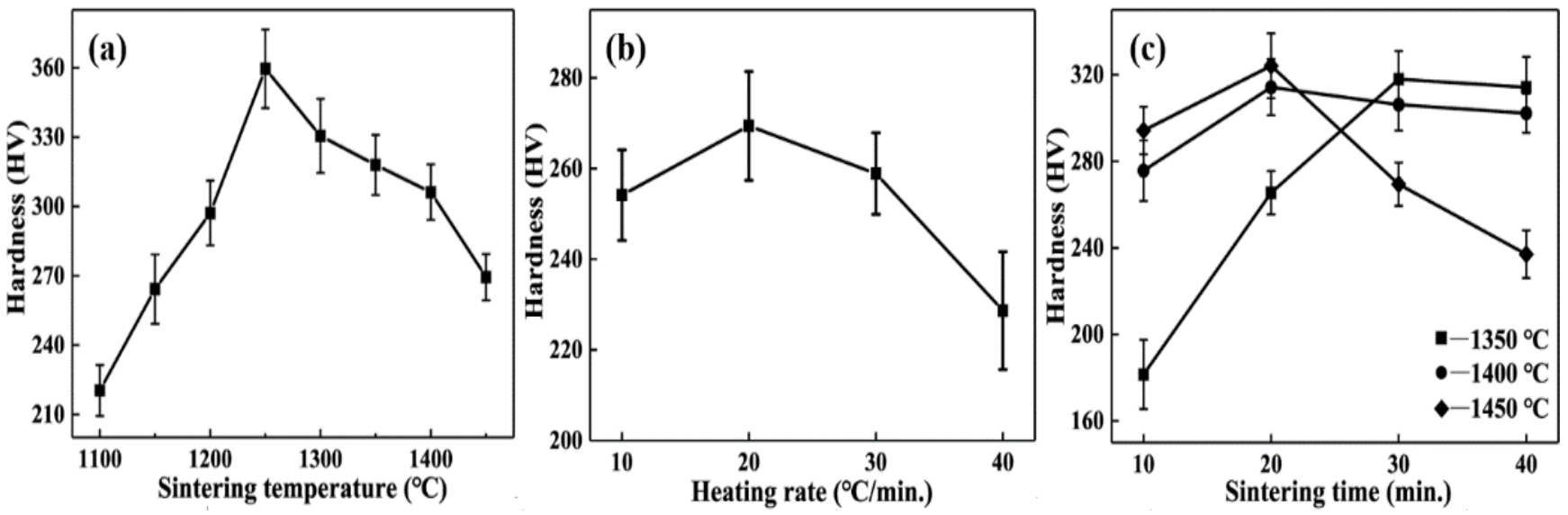

Fig. 9 Effect of (a) sintering temperature, (b) heating rate and (c) holding time on the hardness of obtained compacts.

microhardness firstly increased with the increasing temperature, and reached the maximum value of $359.51 \mathrm{HV}$ at $1250^{\circ} \mathrm{C}$, which was about $10.7 \%$ increase over the maximum hardness value of $321 \mathrm{HV}$ obtained by thermal sintering of the same Mo powder without microwave field, ${ }^{[6]}$ and also much higher than the values reported in other works. ${ }^{[4,14,15,26,27]}$ Then the hardness of the compacts started to decrease when the sintering temperature further increased. The evolution of hardness could be well explained by the compromised effect of density and grain size according to the Hall-Petch equation. ${ }^{[28,29]}$ When the sintering temperature was elevated, the gradually proceeded densification favors the improvement of the hardness, while the over-coarsened grain resulted in the deterioration of the hardness, thus the highest value was obtained at defined temperature with the coordination between density and grain size. This mechanism was also feasible to explain the similar evolution tendency of hardness with the increased heating rates and holding time shown in Fig. $9 \mathrm{~b}$ and c.

(a)

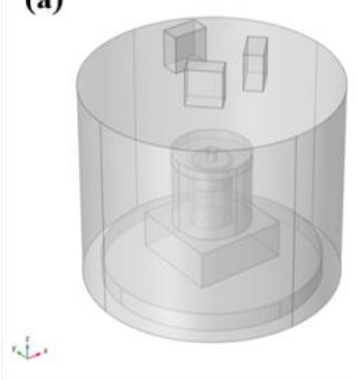

(e)

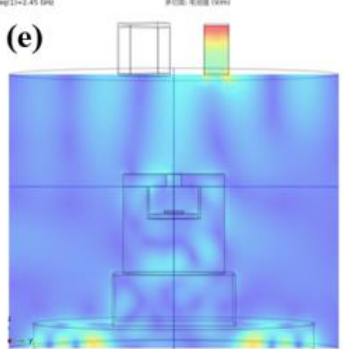

(b)

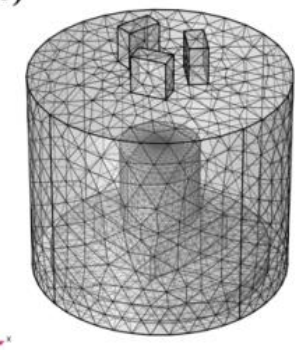

(f)

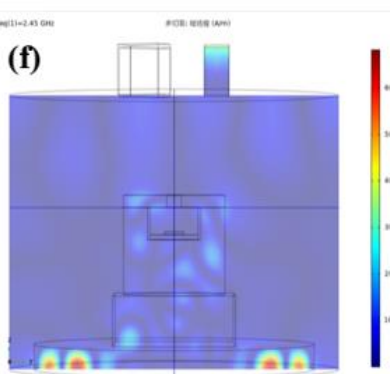

3.7 Finite element simulation of microwave sintering process

To get a better understanding of the sintering mechanism of microwave field, the COMSOL Multiphysics was used to simulate the electromagnetic field distribution during the microwave sintering process. Fig. $10 \mathrm{a}$ and $\mathrm{b}$ illustrate the $3 \mathrm{D}$ diagram and finite element model of the microwave field formed by three rectangular waveguides excited at the $\mathrm{TE}_{10}$ mode. Fig. 10c and d give the schematic distributions of the electric and magnetic field at the ZOY section (In the space rectangular coordinate system, the plane formed by the $\mathrm{Z}$ axis and the $Y$ axis) in the cavity. When the microwave propagated in the furnace cavity and encountered the inner wall of the over, it will be reflected and continuously superimposed to produce a standing wave, which resulted in the formation of nonuniformly distributed electromagnetic field in the cavity. After placing the sample in the microwave field (as shown in Fig. $10 \mathrm{e}$ and $\mathrm{f}$ ), the distribution of electromagnetic field in the furnace cavity was affected to a certain extent due to the
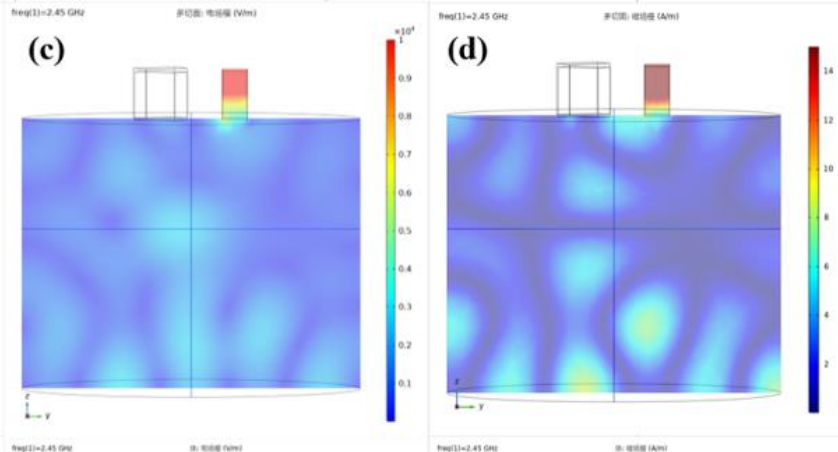

(g)

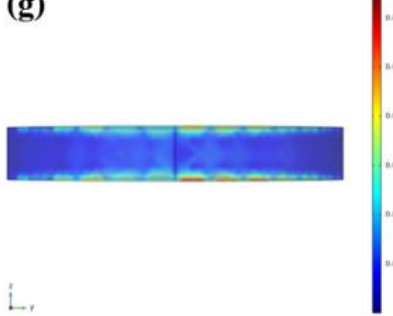

(h)

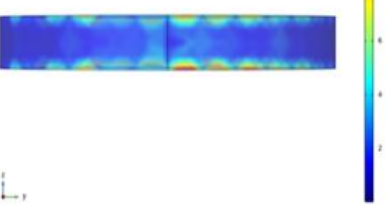

Fig. 10 (a) 3D modeling diagram, (b) finite element model, (c) electric field distribution in microwave empty cavity, (d) magnetic field distribution in microwave empty cavity and (e) electric field distribution, (f) magnetic field distribution, (g) electric field of sample, (h) magnetic field distribution of the sample during microwave sintering. 
microwave absorption by the auxiliary heating material and the molybdenum compact, which weakened the intensity of the electromagnetic field inside the cavity. Microwave energy was absorbed by sample and then converted into heat energy through loss mechanism including dielectric loss caused by electric field, conductance loss and magnetic loss by magnetic field. ${ }^{[30]}$ By analyzing the distribution of electromagnetic field at the cross section of the molybdenum compact (Fig. 10g and h), it was found that the surface had higher electric field and magnetic field density than the inner part of the sample, which suggested that more microwave energy were absorbed by the interior of compact with more heat energy produced, and the volume heating including the arc discharge and magnetic loss could be identified as the main driven-force for densification of Mo compact in the microwave field. ${ }^{[31,32]}$ This heating method was more superior to the heating radiation and conduction from outside to interior of the compact by the thermal sintering process without microwave field, facilitating the formation of fulldensified Mo metal with fine grain size and uniform microstructure. In addition, the various thermal and non-thermal effects induced by microwave field also provided additional driving forces for the formation of sintering necks, ${ }^{[33-35]}$ which had positive effect on the densification process of Mo compact.

\section{Conclusion}

In summary, microwave sintering of nanocrystalline Mo powder was systemically investigated by analyzing the densification behavior and the microstructure evolution during sintering process. Nearly full-densified compact with relative density of $99.8 \%$ and grain size of $2.09 \mu \mathrm{m}$ was obtained at rather low temperature of $1450{ }^{\circ} \mathrm{C}$ for $0.5 \mathrm{~h}$, which is much superior to the compact with density of $99.13 \%$ and grain size of $7 \mu \mathrm{m}$ fabricated by traditional thermal sintering at $1500{ }^{\circ} \mathrm{C}$ for $1 \mathrm{~h}$. Mechanistic investigation reveals that the greatly enhanced driven force of densification is originated from the unique heating way in microwave field, and is responsible for the formation of highlydense and fine-grain compact, which was further examined by the kinetics analysis of densification process at different temperatures.

\section{Acknowledgments}

This work was supported by the National Key Research and Development Program of China (No. 2017YFB0305600), National Natural Science Foundation of China (No. 51904015) and General Program of Science and Technology Development Project of Beijing Municipal Education Commission (No. KM202010005008).

\section{Conflict of Interest}

There is no conflict of interest.

\section{Supporting Information}

Not applicable

\section{References}

[1] H. D Hu, Q. Yin, S. Q. Chen, Y. L. Jia, W. Y. Zhou, H. Y. Li, P. Hu, J. S. Wang, Eng. Sci., 2019, 5, 88-96, doi: $10.30919 / \mathrm{es} 8 \mathrm{~d} 686$.

[2] P. M. Cheng, Z.J. Zhang, G.J. Zhang, J.Y. Zhang, K. Wu, G. Liu, J. Sun, Mater. Sci. Eng. A., 2017, 707, 295-305, doi: 10.1016/j.msea.2017.09.064.

[3] G. Liu, G. Zhang, F. Jiang, Nat. Mater., 2013, 12, 344-350, doi: 10.1038/nmat3544.

[4] S. Majumdar, S. Raveendra, I. Samajdar, P. Bhargava, Acta. Mater., 2009, 57, 4158-4168, doi: 10.1016/j.actamat.2009.05.013.

[5] R. Castro, D. Gouvea, J. Am. Ceram. Soc., 2016, 99, $1105-$ 1121, doi: 10.1111/jace.14176.

[6] P. Hu, T. Y. Chen, X. J. li, J. Y. Gao, J. S. Wang, Int. J. Refract. Met. Hard Mater., 2019, 83, 1-8, doi: 10.1016/j.ijrmhm.2019.104969.

[7] R. Roy, D. Agrawal, S. Gedevanishvili, Nature, 1999, 399, 668-670, doi: 10.1038/21390.

[8] A. Mondal, D. Agrawal, A. Upadhyaya, J. Micro. Pow. E. E., 2010, 44, 28-44, doi: 10.1080/08327823.2010.11689768.

[9] D. Khaled, N. Novas, F. Manzano, Renew. Sust. Energ. Rev., 2018, 82, 2880-2892, doi: 10.1016/j.rser.2017.10.043.

[10] R. Rumman, L. Chuan, C. Quinton, R. Ghomashchi, Int. J. Refract. Met. Hard Mater., 2019, 81, 7-14, doi: 10.1016/j.ijrmhm.2019.02.007.

[11] Y. Jiadong, Y. Zengbin, Y. Juntang, L. Zhiyuan, H. Dongbo, Int. J. Appl. Ceram Tec., 2020, 17, 761-770, doi: 10.1111/ijac.13387.

[12] M. Hou, S. Guo, L. Yang, E. Ullah, Powder. Technol., 2019, 356, 403-413, doi: 10.1016/j.powtec.2019.08.055.

[13] M. Santanu, D. Andriy, D. Vadym, C. Zhe, J. Am. Cream. Soc., 2020, 103, 4876-4893, doi: 10.1111/jace. 17226.

[14] P. Chhillar, J. Adair, A. Adair, Powder. Metall., 2008, 51, 182-187, doi: 10.1179/174329007x178001.

[15] B. H. Duan, Z. Zhang, T. Zhou, T. Nonferr. Metal. Soc., 2019, 29, 1705-1713, doi: 10.1016/s1003-6326(19)65077-6.

[16] D. Akinwekomi, K. Yeung, T. Chak, T. Gary, Int. J. Adv. Manuf. Tech., 2020, 110, 2503-2515, doi: 10.1007/s00170-02005952-0.

[17] C. Maniere, A. Eugene, J. Am. Ceram. Soc., 2017, 100, 24392450, doi: 10.1111/jace.14762.

[18] T. Santos, M. Valente, J. Monteiro, L. Costa, Appl. Therm. Eng., 2011, 31, 3255-3261, doi: 10.1016/j.applthermaleng.2011.06.006.

[19] P. Mishra, G. Sethi, Metall. Mater. Trans. B, 2006, 37, 839845, doi: 10.1007/s11663-006-0066-z.

[20] Y. L. Zhou, W. L. Wang, J. Sun, X. L. Ma, Z. L. Song, Y. P. Mao, Appl. Therm. Eng., 2017, 125, 386-393, doi: 10.1016/j.applthermaleng.2017.07.024.

[21] J. Song, W. L. Wang, A. Dinesh, Materials, 2016, 9, 1-25, doi: 10.3390/ma9040231.

[22] C. Vriezinga, J. Grasman, Appl. Math. Model., 2002, 26, 1029-1038, doi: 10.1016/s0307-904x(02)00058-6.

[23] N. Gupta, V. Midha, J. Demetre, J. Electrochem. Soc., 2019, 146, 4659-4665, doi: 10.1149/1.1392690. 
[24] X. Wu, J. Thomas, W. Davis, J. Appl. Phys., 2002, 92, 33743380, doi: 10.1063/1.1501744.

[25] L. Pérez, C. José Manuel, R. Concepción, J. Am. Ceram. Soc., 2002, 85, 763-768, doi: 10.1111/j.1151-2916.2002.tb00169.x.

[26] R. Wiedemann, U. Martin, A. Müller, Int. J. Refract. Met., 2010, 28, 550-557, doi: 10.1016/j.ijrmhm.2010.03.003.

[27] G. D. Sun, G. H. Zhang, K. H. Chou, Int. J. Refract. Met., 2019, 84, 1-10, doi: 10.1016/j.jijrmh.2019.105039.

[28] D. Wolf, V. Yamakov, A. Mukherjee, Int. J. Mater. Res., 2003, 94, 1091-1097, doi: 10.3139/146.031091.

[29] H. H. Yu, Y. C. Xin, M. Y. Wang, Q. Liu, J. Mater. Sci. Technol., 2018, 34, 248-256, doi: 10.1016/j.jmst.2017.07.022.

[30] Y. Xiao, F. Xu, B. Dong, W. C. Liu, F. Lopez, Materials, 2017, 7, 1-11, doi: 10.3390/met7020047.

[31] W. L. Wang, Z. Liu, J. Sun, Q. L. Ma, C. Y. Ma, Y. L. Zhang, AlchE, 2012, 58, 3852-3857, doi: 10.1002/aic.13766.

[32] Y. K. Feng, W. L. Wang, Y. C. Wang, J. Sun, C. Zhang, S. Qamar, Y. P. Ma, Z. L. Song, Sci. Total. Environ., 2018, 645, 788795, doi: 10.1016/j.scitotenv.2018.07.183.

[33] B. Dong, Y. Xu, X. F. Hu, X. P. Wu, J. Alloys. Compd., 2018, 749, 103-112, doi: 10.1016/j.jallcom.2018.03.231.

[34] J. Cheng, D. Agrawal, Mater. Res. Innov., 2002, 5, 170-177, doi: 10.1007/s10019-002-8642-6.

[35] Z. Peng, J. Hwang, M. Andriese, Appl. Phys. Express., 2012, 5, 1-7, doi: 10.1209/0295-5075/107/30001.

\section{Author information}

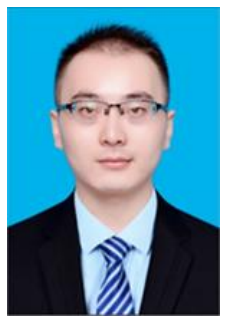

Ruihu Wang is currently a graduate student in the School of Metallurgy Engineering at $X i$ 'an University of Architecture and Technology. He graduated from Xi'an University of Architecture and Technology with a bachelor's degree in 2018. His current research is microwave sintering of refractory metals.

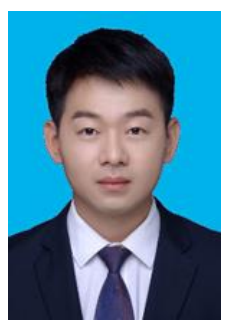

Shilei Li is currently a graduate student in the Faculty of Materials and Manufacturing at Beijing University of Technology. His current research is rare-earth-doped tungsten cathode materials.

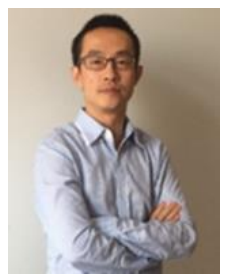

Peng $\mathbf{H u}$ is currently a professor at Faculty of Materials and Manufacturing, Beijing University of Technology. He received his $B$. $S$. degree from Beijing University of Chemical Technology in 2000, and obtained his Ph.D. degree from Institute of Process Engineering (IPE), Chinese Academy of Sciences (CAS) in 2008. From 2012 to 2013, he worked as a Research Fellow at Nanyang Technological University. He joined Beijing University of Technology at 2017 after working 17 years in IPE. His research interests focus on plasma enhanced chemical process, aiming to develop new strategy for large-scale synthesis, structure control and functionalization of nanomaterials for advanced applications.

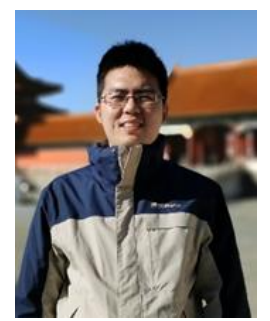

Shuqun Chen is currently a Lecturer at Faculty of Materials and Manufacturing, Beijing University of Technology. He received his Ph.D. degree from Queen Mary University of London at 2016, under the supervision of Dr. Russell Binions and Prof. Steve Dunn. In October 2016, he joined Beijing University of Technology as a postdoctoral researcher and obtained the lectureship at late 2018. His research interests focus on fabricating functional thin films and coatings by CVD and PVD methods.

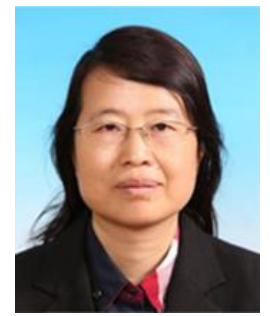

JinShu Wang is a professor at Faculty of Materials and Manufacturing in Beijing University of Technology (BJUT). She received her Ph.D. degree from the College of Materials Science and Engineering, BJUT, in 1999. From 2002 to 2004, she had worked as a postdoctoral researcher in Tohoku University, Japan. Her research interests include refractory metal-based electronic emission materials, renewable energy and environmental materials. She has published over 200 peer reviewed journal papers (Adv Funct Mater, Appl Catal B: Environ, J Mater Chem A, ect.) and 2 books. She has authorized over 40 invention patents of China and 2 American invention patents. She is a senior committee member of Vacuum Electron Society, Chinese Electronics Society, committee member of Chinese Corrosion \& Protection Society, member of Society of Metallurgical Physical chemistry, and member of Photocatalysis Industry Association of China. She is also an editor of journals of Powder Metallurgy Technology, Tungsten, Vacuum electronics Technology, ect.

Publisher's Note Engineered Science Publisher remains neutral with regard to jurisdictional claims in published maps and institutional affiliations. 